\title{
BUSCA DE PARALELISMO ENTRE CONHECIMENTO PEDAGÓGICO DO CONTEÚDO E PROCESSO DE RACIOCÍNIO E AC̣ÃO PEDAGÓGICA
}

\author{
Daniel Marcon*, Amândio Braga dos Santos Graça**, Juarez Vieira do Nascimento***
}

RESUMO: Ao apresentar as propostas do conhecimento pedagógico do conteúdo e do processo de raciocínio e da ação pedagógica, Shulman não explicitou, em sua teoria, as possíveis relações entre elas. Visando a analisar tais relações, este ensaio colocou lado a lado esses dois temas nucleares nos estudos de Shulman e, respaldado por outras investigações que abordam esses temas, buscou descobrir como podem se inter-relacionar na formação inicial de professores. As informações analisadas permitem inferir que ambas as propostas mantêm estreita, recíproca e quase interdependente relação entre si, de modo que se permeiam, se complementam e somam esforços no sentido comum de transformar os conhecimentos do conteúdo dos futuros professores em conhecimentos ensináveis aos alunos. A consideração dessas questões pelos programas de formação e sua implementação, por meio de práticas pedagógicas e suas reflexões, têm potencial para integrar esses elementos e qualificar a formação inicial dos futuros professores.

Palavras-chave: Formação Inicial de Professores; Conhecimentos Docentes; Práticas Pedagógicas; Reflexões.

THE SEARCH OF PARALLELISM BETWEEN PEDAGOGICAL KNOWLEDGE OF THE CONTENTS AND THE PROCESS OF REASONING AND PEDAGOGICAL ACTION

ABSTRACT: While presenting the proposals of the pedagogical knowledge of the contents and the pedagogical action, Shulman did not set out in his theory the possible relations between them. Willing to analyze such relations, this essay put these two core themes in Shulman studies side by side and supported by other investigations that address these themes, tried to find out how they may inter-relate in the initial teacher training. The analyzed information allow to infer that both proposals keep a strict, reciprocal and almost interdependent relation between them, so that they permeate themselves, and complete and make efforts to each other in the common sense to transform the contents knowledge of the future teachers into teachable knowledge to pupils. The consideration of these questions by the training programs and its implementation through pedagogical practices and their reflections can potentially integrate these elements and qualify the initial training of future teachers.

Keywords: Initial Teacher Training; Teaching Knowledge; Pedagogical Practices; Reflections.

* Doutor em Ciências do Desporto pela Universidade do Porto (UP . Portugal) e Professor Assistente da Universidade de Caxias do Sul (UCS). E-mail: dmarcon@ucs.br

* * Doutor em Ciências do Desporto pela Universidade do Porto (UP - Portugal) e Professor Associado da Faculdade de Desporto da Universidade do Porto (UP - Portugal). E-mail: agraca@fade.up.pt

* * Doutor em Ciências do Desporto pela Universidade do Porto (UP - Portugal); Professor Associado da Universidade Federal de Santa Catarina (UFSC) e Pesquisador do Conselho Nacional de Desenvolvimento Tecnológico (CNPq). E-mail: juarezvn@cds.ufsc.br 


\section{Introdução}

Aliando a sagacidade aguçada de uma astuta raposa e a incisiva persistência de um ouriço-cacheiro, como alude Wilson (2004), Lee Shulman encabeçou projetos de investigação que expandiram e aprofundaram, de forma indelével, a compreensão nos domínios do conhecimento e raciocínio profissional, da pedagogia da formação profissional, da avaliação do ensino e do conteúdo e caráter da investigação. Ao longo dos anos, os caminhos percorridos por Shulman foram iluminados por algumas de suas propostas mais eminentes, entre as quais se destaca a do conhecimento pedagógico do conteúdo.

Pela grande atenção recebida nos últimos anos, a participação do conhecimento pedagógico do conteúdo tem sido ressaltada tanto na formação inicial quanto na formação continuada e na atuação profissional dos professores, o que tem contribuído para o avanço do conhecimento sobre o tema (ABELL; LEDERMAN, 2007; CHEN, 2004; GRABER, 1995; GRAÇA, 1997, 2001; GRAÇA; JANUÁRIO, 2000; GRIFFIN et al., 1996; KIND, 2009; MIZUKAMI, 2004; PARK; OLIVER, 2008; SEGALL, 2004). Além de compor a base de conhecimentos para o ensino, juntamente com os conhecimentos dos alunos, do conteúdo, pedagógico geral e do contexto, ao conhecimento pedagógico do conteúdo é atribuída a responsabilidade de integrar os demais componentes da base, visando ao ensino do conteúdo aos alunos (COCHRAN et al., 1991; ENNIS, 1994; GROSSMAN, 1990; JENKINS; VEAL, 2002; SHULMAN, 1987).

Essas pesquisas permitem reconhecer o conhecimento pedagógico do conteúdo como aquele que o estudante-professor utiliza para, a partir dos seus objetivos, da realidade dos alunos e das características do contexto de ensino e aprendizagem, convocar, gerir e fazer interagir os conhecimentos da base de conhecimentos para o ensino, visando à adaptação, à transformação e à implementação do conhecimento do conteúdo a ser ensinado, de modo a torná-lo compreensível e ensinável aos alunos.

Percebe-se que, ao ser confrontado com dilemas e situações-problema, o conhecimento pedagógico do conteúdo desencadeia uma sequência de tarefas que, em conjunto com diferentes momentos de reflexão, encaminha tanto ao alcance dos objetivos da prática pedagógica 
quanto à aprendizagem dos alunos (ALTET, 2001; GIMENO SACRISTÁN, 1995; HEGARTY, 2000; MEIRIEU, 2002; PÉREZGÓMEZ, 1995; SCHÖN, 1995; SEBREN, 1995; SHULMAN, 1987; TSANGARIDOU; O' SULLIVAN, 1994).

É justamente esse o espaço por onde a presente análise pretende adentrar a formação inicial de professores. Seu objetivo é, portanto, estabelecer um paralelo entre as tarefas desempenhadas pelo conhecimento pedagógico do conteúdo e as etapas do processo de raciocínio e ação pedagógica, ambos propostos por Shulman (1987), de modo a verificar como convivem, interagem ou, eventualmente, se sobrepõem umas às outras.

A importância de se investigar tal paralelismo foi destacada, justamente, por Shulman (1993), quando admitiu ter, ele próprio, contribuído para uma relativa confusão instaurada entre três distintos conceitos do conhecimento pedagógico do conteúdo:

1) uma forma de entendimento que professores possuem (ou deveriam possuir) que distingue seu pensamento e raciocínio daquela característica de mero expert no assunto; 2) parte da base de conhecimento para o ensino, um corpo de conhecimento científico, habilidade e - em certa medida - disposição, que distingue ensinar como uma profissão e inclui aspectos de racionalidade técnica e de capacidades de julgamento, improvisação e intuição, que Schön chamou "reflexão na ação"; 3) um processo de raciocínio e ação pedagógica por meio do qual professores aplicam seu conhecimento eficientemente para resolver o problema de ensinar algo em um contexto específico; desempenham seus planos cuidadosamente, aperfeiçoando-os e improvisando de forma espontânea quando situações de ensino imprevisíveis e inevitáveis surgem; e desenvolvem novos conhecimentos, intuições e disposições (SHULMAN, 1993, p. 56-57, tradução nossa).

A estratégia utilizada para tentar dar conta do objetivo deste ensaio e lançar luz sobre essa relativa confusão a que se refere Shulman (1993) foi a de colocar, lado a lado, suas duas propostas (SHULMAN, 1987). Buscou-se esmiuçar as características e peculiaridades dessa relação com o respaldo das produções científicas que, ao longo dos anos, se preocuparam em refletir sobre a construção e o desenvolvimento tanto do conhecimento pedagógico do conteúdo quanto do processo de raciocínio e ação pedagógica.

O desafio de elucidar como o conhecimento pedagógico do conteúdo dos futuros professores se constrói no decorrer do processo de for- 
mação inicial vem sendo assumido pelos autores nos últimos anos, e este ensaio teórico integra os esforços empreendidos nesse sentido. Mais especificamente, este é um dos ensaios que compõem a fundamentação teórica da tese realizada pelo autor principal, sob orientação dos segundos autores, no Programa de Doutoramento em Ciências do Desporto da Universidade do Porto, Portugal.

Para uma melhor organização das informações discutidas neste ensaio, elas foram divididas em três partes. Inicialmente, é apresentado o modelo de raciocínio e ação pedagógica. $\mathrm{Na}$ sequência, em diferentes momentos de reflexão, é analisado como o conhecimento pedagógico do conteúdo gere suas funções nas práticas pedagógicas. Por último, algumas ilações são elaboradas sobre as relações entre o processo de raciocínio e ação pedagógica e o conhecimento pedagógico do conteúdo.

\section{Processo de raciocínio e ação pedagógica}

Proposto originalmente por Shulman (1987, p. 12), o processes of pedagogical reasoning and action, ou processo de raciocínio e ação pedagógica, retrata uma sequência de eventos desencadeada nas práticas pedagógicas cujo objetivo principal é possibilitar ao estudante-professor a construção de conhecimentos relativos a como ensinar diferentes assuntos, para diferentes alunos e em contextos distintos. Para isso, Shulman (1987, p. 15) descreve o processo de raciocínio e ação pedagógica como um ciclo formado por seis elementos, nomeadamente: compreensão, transformação, instrução, avaliação, reflexão, e nova compreensão, que abrangem diferentes etapas do envolvimento do estudante-professor com sua base de conhecimentos e a prática pedagógica, no sentido da construção do seu conhecimento pedagógico do conteúdo. A inter-relação desses seis elementos foi sugerida por Salazar (2005, p. 7), em um diagrama construído a partir do próprio processes of pedagogical reasoning and action, de Shulman (1987, p. 15), como ilustrado na Figura 1: 
Figura 1. Modelo de raciocínio e ação pedagógica (tradução nossa)

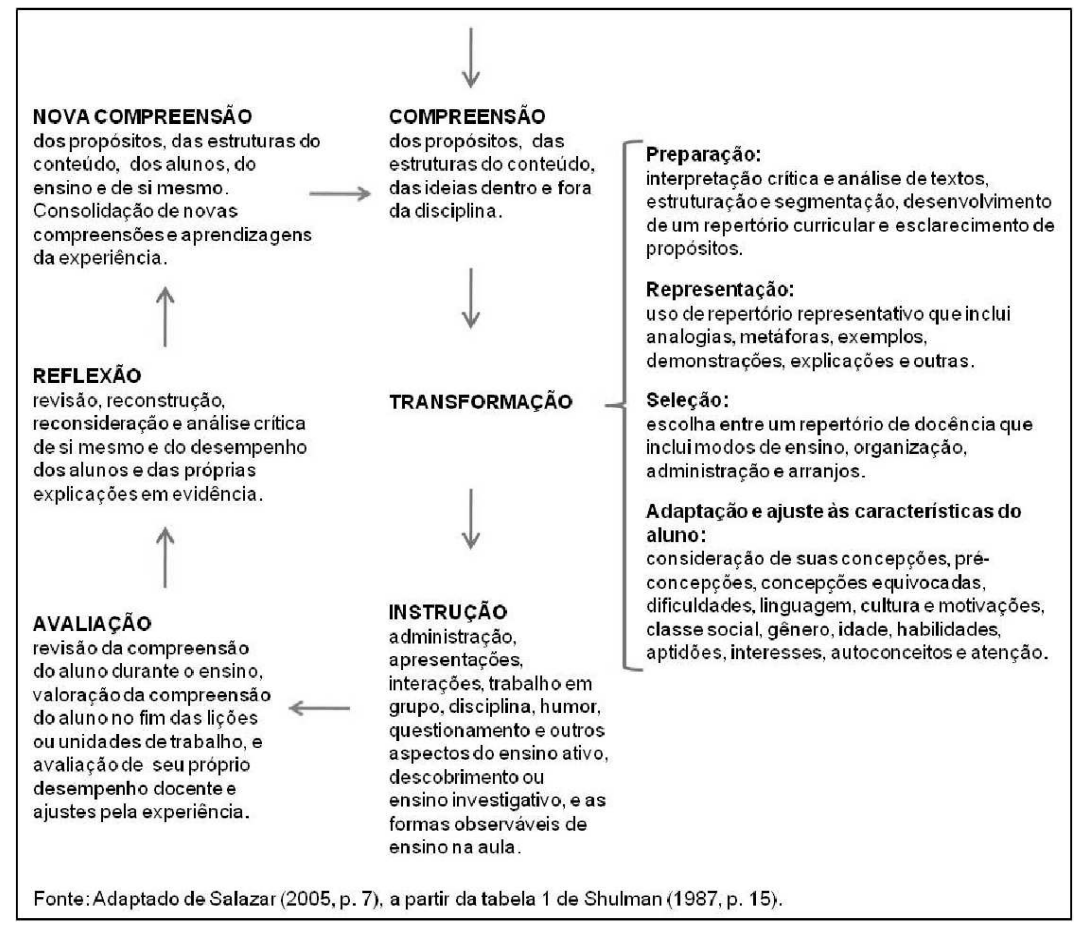

A seguir, são apresentados, de forma sintetizada, cada um desses seis elementos:

1. Compreensão: propõe a construção de um nível de compreensão mínimo sobre os propósitos e a forma como é estruturada determinada área do conhecimento e sobre as ideias relacionadas tanto com essa mesma área quanto com outras ideias sobre outras áreas. Diferentes autores explicam que o desenvolvimento da capacidade de compreensão busca fazer com que os estudantes-professores não apenas conheçam um assunto específico, mas que diversifiquem ao máximo suas formas de compreender, de saber e de interpretar o assunto (GROSSMAN et al., 1989; SHULMAN, 1987; SIEDENTOP, 2002; VALLI; RENNERT-ARIEV, 2002);

2. Transformação: refere-se ao tratamento e à gestão a que são submetidos os conhecimentos, integrantes da base de conhecimentos, visando à construção de uma concepção e de uma representação particu- 
lar e individualizada do estudante-professor sobre a matéria a ser ensinada. A exemplo de Shulman (1987), Calderhead (1988) e Grossman et al. (1989) também interpretam essa transformação a partir das alterações às quais os estudantes-professores impõem seus conhecimentos relacionados ao conteúdo, com o objetivo de gerir a construção do conhecimento dos seus alunos.

Para que as respectivas convocação, gestão e transformação dos conhecimentos do conteúdo sejam possíveis, Shulman (1987, p. 1617) sugere, e a literatura corrobora, a combinação de cinco diferentes subprocessos: (1) preparação ou interpretação crítica, que pode ser analisada sob a ótica tanto dos critérios de seleção dos materiais didáticos quanto da própria avaliação da sua adequação, ou não, aos objetivos, ao contexto e aos alunos; (2) representação das ideias, que se refere às análises, "analogias, ilustrações, metáforas, exemplos, experimentações, simulações, dramatizações, músicas, filmes, casos de ensino, demonstrações" e demais formas de representar o assunto para os alunos visando à construção de "pontes" entre a compreensão que o estudante-professor tem sobre os conhecimentos em sua base de conhecimentos e aquilo que se espera dos alunos (MIZUKAMI, 2004, p. 6); (3) seleção das estratégias de ensino, que diz respeito à utilização não apenas dos métodos tradicionais de ensino e aprendizagem, mas de estratégias alternativas de ensino, de organização e de gestão que possibilitem a exploração e a construção, individual e/ou coletiva, de novos conhecimentos por parte dos alunos; (4) adaptação, que são todas as modificações possíveis de serem implementadas na prática pedagógica visando a tornar o assunto acessível aos alunos, independentemente de quais sejam suas experiências ou concepções anteriores, níveis de conhecimento, interesses e habilidades; e (5) adaptações "conjuntas", cujo desafio é não apenas levar em conta as características e particularidades de cada um dos alunos, mas analisá-las de forma coletiva e integrada, percebendo as diferentes individualidades que estruturam o perfil social daquele grupo (GRIFFIN et al., 1996; MIZUKAMI, 2004; SHULMAN, 1987; VALLI; RENNERT-ARIEV, 2002);

3. Instrução: envolve o desempenho observável do estudante-professor na implementação de diferentes estratégias de ensino, incluindo aspectos pedagógicos “cruciais" (SHULMAN, 1987, p. 17), como organização e gestão do contexto de ensino e aprendizagem; utilização de explicações, descrições e demonstrações claras e compreensíveis aos 
alunos; e acompanhamento, assistência e interação com os alunos a partir de suas concepções ou questionamentos, respostas ou reações, admiração ou ceticismo (CARTER, 1990; GROSSMAN et al., 1989; SHULMAN, 1987; VALLI; RENNERT-ARIEV, 2002);

4. Avaliação: refere-se tanto aos processos formais de avaliação da aprendizagem e da evolução dos alunos quanto à coleta de informações subjetivas a partir da interação com eles. Essas informações se referem ao alcance, ou não, dos objetivos da prática pedagógica, seja para cada aluno em particular, seja para a turma de alunos. O foco da avaliação, nesse caso, não são os alunos, mas o desempenho e a influência do estudante-professor para o alcance dos objetivos.

Portanto, seja de maneira direta, seja de maneira indireta, de modo formal ou informal, o objetivo da etapa de avaliação no processo de raciocínio e ação pedagógica, como afirmam vários autores, é oferecer ao estudante-professor um feedback da sua atuação docente e da sua capacidade de transformar seus próprios conhecimentos (relacionados ao conteúdo) em conhecimentos que sejam compreendidos, assimilados e aprendidos pelos alunos (GROSSMAN et al., 1989; PARK; OLIVER, 2008; SHULMAN, 1987; VALLI; RENNERT-ARIEV, 2002; WOODS et al., 2000);

5. Reflexão: tem como meta analisar a maneira como se desenvolveu a prática pedagógica, visando a reconstruí-la e a revivê-la, para, assim, recapitular como os eventos ocorreram, quais emoções surgiram e como os aprendizados se deram. Nóvoa (1995), Pérez-Gómez (1995) e Schön (1995) ensinam que essas reflexões têm como objetivo principal fazer uma revisão da prática pedagógica, comparando os objetivos iniciais com aqueles efetivamente obtidos, extraindo dessa análise elementos que orientem futuras situações de ensino e aprendizagem;

6. Nova compreensão: de acordo com Ennis (1994), Shulman (1987) e Woods et al. (2000), esse é o momento em que o estudante-professor se dá conta de que, a partir de uma desestabilização inicial gerada por dilemas ou situações-problema, conseguiu reestruturar sua base de conhecimentos, seja reconstruindo os que a integravam, seja construindo novos a partir daqueles. Esse processo de autoesclarecimento pode se desenvolver não somente com conhecimentos novos ou reestruturados, mas também com os antigos. Nesse sentido, diferentes autores têm defendido que, nas reflexões sobre as práticas pedagógicas, os estudantes-pro- 
fessores podem se dar conta de que determinado conhecimento pode ser utilizado para solucionar uma situação-problema específica, o que não compreendiam anteriormente; era um conhecimento que, apesar de possuírem, não sabiam que poderia ser utilizado em certas circunstâncias (GROSSMAN et al., 1989; PARK; OLIVER, 2008; VALLI; RENNERTARIEV, 2002). Essa situação pode ser interpretada, pois, uma nova compreensão acerca de um antigo conhecimento que, consequentemente, adquire novo status na base de conhecimentos.

Apesar de o processo de raciocínio e ação pedagógica proposto por Shulman (1987) ser apresentado nessas seis etapas, é ressaltado por ele e por outros autores que sua utilização nas práticas pedagógicas não será sequencial ou hierárquica, como se o início de um estágio dependesse do encerramento de outro (ALTET, 2001; GRAÇA, 1997; HEGARTY, 2000; SALAZAR, 2005; TARDIF; RAYMOND, 2000). Outro aspecto a destacar, como o fazem Behets e Vergauwen (2006), Ennis (1994) e Park e Oliver (2008), é que o caráter dinâmico, instável e imprevisível das práticas pedagógicas impossibilita sua organização e estruturação prévia, impondo ao estudante-professor o desafio de gerenciar essas questões simultaneamente, para alcançar seus objetivos e a aprendizagem dos alunos.

Uma vez apresentadas as diferentes etapas do processo de raciocínio e ação pedagógica, e reconhecendo a relevância de suas proposições para a formação dos futuros professores, pretende-se, a partir deste momento, direcionar o foco de análise para o conhecimento pedagógico do conteúdo e a maneira como gere suas funções nas práticas pedagógicas.

\section{Reflexões no processo de construção do conhecimento pedagógico do conteúdo}

O estudo dos diferentes momentos de reflexão relacionados à prática profissional do professor não é original, já que tem sido amplamente debatido nos últimos anos (GIMENO SACRISTÁN, 1995; NÓVOA, 1995; PARK; OLIVER, 2008; PÉREZ-GÓMEZ, 1995; PERRENOUD, 2002; SCHÖN, 1995; SEBREN, 1995; TSANGARIDOU; O' SULLIVAN, 1994; VALLI; RENNERT-ARIEV, 2002; ZEICHNER, 1995, 2008). Em vez de prosseguir com o debate a respeito das reflexões realizadas antes, durante e depois das práticas pedagógicas, este ensaio 
buscou se apoiar no lastro teórico construído por esses estudos para analisar a possível relação estabelecida entre a base de conhecimentos para o ensino, o processo de raciocínio e ação pedagógica e as modalidades de práticas pedagógicas, no sentido da construção do conhecimento pedagógico do conteúdo dos futuros professores.

A literatura consultada permite supor que a intersecção desses três momentos de reflexão está na seleção de informações a partir dos dilemas e das situações-problema, sem as quais o conhecimento pedagógico do conteúdo não saberia nem por onde começar e nem traçaria seus objetivos na prática pedagógica. O início da participação do conhecimento pedagógico do conteúdo depende, portanto, das informações sobre o contexto de ensino e aprendizagem, essas advindas de diferentes momentos de reflexão (BEHETS; VERGAUWEN, 2006; PARK; OLIVER, 2008).

Ao se posicionar ante situações de ensino e aprendizagem reais, simuladas ou fictícias, e tanto vividas pessoalmente quanto pelos colegas ou professores, o objetivo do estudante-professor é, por intermédio de suas reflexões, extrair informações relevantes da prática pedagógica (SEBREN, 1995; TSANGARIDOU; O’ SULLIVAN, 1994), de modo a alimentar o conhecimento pedagógico do conteúdo e fazê-lo gerir a busca da solução dos dilemas e das situações-problema detectadas (PARK; OLIVER, 2008).

Para que o estudante-professor possa refletir de maneira consciente e objetiva, a literatura sublinha que sua base de conhecimentos necessita estar provida de conhecimentos oriundos de diferentes fontes e relacionados a todas as instâncias do processo de ensino e aprendizagem, como, por exemplo, os conhecimentos dos alunos; do conteúdo; pedagógico geral; do contexto educacional; e pedagógico do conteúdo (BEHETS; VERGAUWEN, 2006; CALDERHEAD, 1988; COCHRAN et al., 1991; GIMENO SACRISTÁN, 1995; GRAÇA, 2001; GROSSMAN, 1990; MIZUKAMI, 2004).

De modo geral, as proposições dos autores analisados permitem inferir que a quantidade de e a qualidade das informações extraídas do meio dependerão das características da prática pedagógica e, principalmente, da consistência dos conhecimentos disponibilizados na base de conhecimentos e da estrutura do conhecimento pedagógico do conteúdo. Tanto a base de conhecimentos quanto o conhecimento pedagógico do 
conteúdo, além de serem influenciados pelas práticas pedagógicas, também determinam o nível de criticidade das reflexões do estudante-professor.

\section{Reflexões antes da prática pedagógica}

Conforme sugerem estudiosos como Nóvoa (1995), PérezGómez (1995) e Schön (1995), no período que antecede a intervenção pedagógica, denominado "reflexão para a ação", é indicado que os programas de formação e os professores-formadores implementem estratégias que coloquem os estudantes-professores diante de diferentes contextos de ensino e aprendizagem.

Essas estratégias podem ser estruturadas, segundo Valli e Rennert-Ariev (2002), por exemplo, sob a forma de observações orientadas de situações de ensino e aprendizagem fictícias ou simuladas, ao vivo ou gravadas em vídeo; de estudos de caso de aulas, de professores ou de alunos; de análises tanto de práticas pedagógicas dos colegas quanto de aulas ministradas por professores experientes; de debates com a participação dos colegas e dos professores-formadores; bem como de pesquisas e apresentações de trabalhos, tanto individual quanto coletivamente, relacionadas ao processo de ensino e aprendizagem.

Diferentes autores atribuem a experiências dessa natureza a virtude de confrontar os estudantes-professores com diferentes dilemas e situações-problema, que lhes lançam desafios e lhes permitem analisar o comportamento do seu conhecimento pedagógico do conteúdo diante de diferentes realidades (MEIRIEU, 2002; PÉREZ-GÓMEZ, 1995; SEBREN, 1995), verificando como cumpre suas funções de receber as informações advindas das reflexões; convocar os conhecimentos na base de conhecimentos; processar e fazer interagir essas informações e esses conhecimentos; e propor estratégias de intervenção. É destacado na literatura, inclusive, que essas experiências, além de reestruturarem o conhecimento pedagógico do conteúdo, ampliam e fortalecem os conhecimentos que integram a base de conhecimentos e aperfeiçoam a capacidade do estudante-professor de realizar reflexões sobre práticas pedagógicas com diferentes características, seja antes, durante ou após a sua realização (BEHETS; VERGAUWEN, 2006; MEIRIEU, 2002; PÉREZ-GÓMEZ, 1995; SEBREN, 1995).

Park e Oliver (2008) defendem que esses objetivos são alcançados à medida que os dilemas, gerados na prática pedagógica, são absorvi- 
dos por meio de reflexão e enviados para o conhecimento pedagógico do conteúdo, que, por sua vez, busca, na base de conhecimentos, os conhecimentos relacionados e com potencial de solução. Esse processo gera, conforme descreve Schön (1995, p. 85), "confusão e incerteza" no estudante-professor, pois sua base de conhecimentos é desestabilizada, suas concepções sobre o assunto são testadas e a maneira como interpreta seu ensino é colocada em xeque, o que produz importantes mudanças na base de conhecimentos e, por consequência, no conhecimento pedagógico do conteúdo (CALDERHEAD, 1988; GROSSMAN et al., 1989; SCHÖN, 1995; SHULMAN, 1987).

Além desses objetivos, essa etapa de reflexão para a ação também pode assumir um caráter de diagnóstico ou de sondagem, como propõem, respectivamente, Tani (1995) e Meirieu (2002), quando as preocupações do estudante-professor se direcionam à prática pedagógica posterior, na qual assumirá o papel de professor-estudante. Nesse caso, é feito um exercício de pré-visão, na tentativa de dissecar o contexto onde se realizará a aula, para dele extrair informações que sejam úteis. Como explicam Calderhead (1988) e Sebren (1995), esse processo de levantamento das principais demandas da situação de ensino e aprendizagem subsidia tanto a elaboração do planejamento da aula quanto o estabelecimento de objetivos a serem alcançados e de estratégias pedagógicas, que viabilizem seu alcance.

Considerando sua importância na construção do conhecimento pedagógico do conteúdo, autores como Behets e Vergauwen (2006) e Tsangaridou e O' Sullivan (1994) advertem que as estratégias implementadas no período de reflexão para a ação necessitam ser elaboradas de maneira a exigir o máximo desse conhecimento, impondo-lhe dificuldades, dilemas e situações-problema o mais próximos possível daquelas presentes nas situações reais de ensino e aprendizagem.

Destaca-se, a partir da análise das proposições da literatura a respeito das reflexões que antecedem a realização das práticas pedagógicas, que elas possibilitam o desenvolvimento das etapas de compreensão e de transformação, integrantes do processo de raciocínio e ação pedagógica. 


\section{Reflexões durante a prática pedagógica}

$\mathrm{Na}$ linha de raciocínio aqui apresentada, relativamente à inserção gradual na prática docente, o futuro professor ainda não participou de práticas pedagógicas nas quais pudesse assumir o papel de professor-estudante, e suas reflexões direcionaram-se para práticas pedagógicas fictícias, simuladas ou ministradas pelos colegas ou pelos professores. Dessa forma, em todas as suas reflexões, o estudante-professor necessitou fazer um exercício de imaginação, como se aquelas situações estivessem ocorrendo com ele, e como se fosse ele quem tivesse de responder aos desafios impostos pelas situações (CALDERHEAD, 1988; MEIRIEU, 2002). Por isso, além de não influenciar a realidade, o estudante-professor também não foi significativamente afetado por ela, independentemente de quais tenham sido suas decisões pedagógicas.

Entretanto, Ennis (1994) argumenta que, durante as práticas pedagógicas, o estudante-professor deixa de ser expectador e assume o papel de protagonista, e, por interagir com alunos reais, em situações reais de ensino e aprendizagem, suas decisões desencadeiam consequências que ele necessita gerir e pelas quais ele próprio tem de se responsabilizar.

Práticas pedagógicas com essas características submetem o conhecimento pedagógico do conteúdo, como explicam Behets e Vergauwen (2006) e Formosinho (2001), a um grau de exigência que é, em alguns casos, muito próximo daquele encontrado somente nos estágios curriculares ou na própria atuação profissional. Do mesmo modo, Valli e Rennert-Ariev (2002) defendem que, assim, é possibilitada ao estudanteprofessor uma formação contextualizada e que considere tanto a realidade social e educacional quanto algumas facetas da própria profissão docente.

Para que isso efetivamente ocorra, é recorrente na literatura a necessidade de que os programas de formação proponham e implementem diferentes modalidades de práticas pedagógicas, permitindo que os estudantes-professores, ao longo da formação inicial, ministrem aulas em grupo e individualmente; na própria instituição de ensino superior e na escola; para seus colegas e para alunos em idade escolar; para pequenos grupos e para turmas inteiras; e desde uma única atividade até a unidade didática completa. É de cada uma dessas modalidades de prática pedagógica que se originam, simultaneamente, diversos estímulos, dilemas e 
situações-problema que, ao mesmo tempo que desafiam e aperfeiçoam o conhecimento pedagógico do conteúdo, exigem sua intervenção para solucioná-los (BEHETS; VERGAUWEN, 2006; GIMENO SACRISTÁN, 1995; MARCON et al., 2007; MEIRIEU, 2002; PARK; OLIVER, 2008; SETTON, 2002).

No processo de reflexão na ação, conforme denominam autores como Nóvoa (1995), Pérez-Gómez (1995) e Schön (1995), o estudanteprofessor dedica sua atenção para o contexto de ensino e aprendizagem que se materializa na sua frente, de onde, a partir de critérios construídos em todas as experiências e vivências anteriores, e que estão armazenados na sua base de conhecimentos, necessita extrair informações relevantes (SEBREN, 1995; ZEICHNER, 1995). Ao fazer uso desses critérios, o estudante-professor ativa todos os seus sentidos e apura sua sensibilidade para absorver da prática pedagógica os dilemas e as situações-problema que se sobressaem (GIMENO SACRISTÁN, 1995; MEIRIEU, 2002; SET'TON, 2002; TSANGARIDOU; O' SULLIVAN, 1994).

Nessa etapa, a reflexão na ação também assume o caráter de diagnóstico proposto por Meirieu (2002) e Tani (1995), tal como ocorre na reflexão para a ação. Ao analisar o caráter de diagnóstico da reflexão na ação, Calderhead (1988) e Park e Oliver (2008) explicam que são empregados conhecimentos da base de conhecimentos com o objetivo de dissecar o contexto, separar as informações por categorias, selecionar as que têm maior potencial para causar problemas ou dificuldades, e estabelecer prioridades.

Percebe-se que esse diagnóstico tem sua participação destacada por exercer as funções de filtragem e de seleção das informações advindas do contexto de ensino e aprendizagem, o que enaltece sua importância para o próprio conhecimento pedagógico do conteúdo, que depende dessas informações para intervir com sucesso nas práticas pedagógicas. Em função da qualidade das informações que disponibilizar para o conhecimento pedagógico do conteúdo, o diagnóstico terá poder, inclusive, de determinar os rumos do processo de ensino e aprendizagem.

Uma vez recebidas essas informações, Gimeno Sacristán (1995) e Grossman et al. (1989) esclarecem que o conhecimento pedagógico do conteúdo inicia, efetivamente, sua participação na situação de ensino e aprendizagem, quando seleciona a situação-problema prioritária e convoca, na base de conhecimentos, tanto os conhecimentos construídos 
durante o planejamento da aula, nas reflexões antes da prática pedagógica, quanto todos os demais que se relacionem com a situação de ensino e aprendizagem em questão. A análise desses processos de seleção e de convocação permite supor que as informações extraídas da situação de ensino e aprendizagem pelo diagnóstico façam com que o conhecimento pedagógico do conteúdo provoque uma turbulência na estrutura interna da base de conhecimentos, de modo a encontrar meios que possibilitem a solução da situação-problema, o que vem a corroborar alguns indícios da literatura (CALDERHEAD, 1988; CARTER, 1990; GROSSMAN et al., 1989; PARK; OLIVER, 2008; SCHÖN, 1995; ZEICHNER, 1995).

As estratégias de formação, assim concebidas, evidenciam a participação da etapa de compreensão do processo de raciocínio e ação pedagógica, à medida que geram uma desestabilização inicial na base de conhecimentos do estudante-professor e testam seus conhecimentos e suas concepções a respeito da matéria e de seu ensino. Da mesma forma, observase a participação de subprocessos da etapa de transformação do processo de raciocínio e ação pedagógica, já que conhecimentos necessários para a situação de ensino e aprendizagem estão sendo acionados a partir da base de conhecimentos pelo conhecimento pedagógico do conteúdo.

Independentemente das origens ou das características da situação-problema, os conhecimentos que se fazem necessários para sua solução estão relacionados, de uma forma ou de outra, às proposições de Altet (2001) quanto aos conhecimentos docentes, ou seja, aos (1) conhecimentos para ensinar, que são, além do próprio conhecimento pedagógico do conteúdo, os conhecimentos do conteúdo para ensinar, dos alunos, pedagógico geral e do contexto; ou aos (2) conhecimentos a serem ensinados, que, representados pelo conhecimento do conteúdo a ser ensinado, dizem respeito especificamente ao assunto em pauta.

A dinâmica e complexa interação dos conhecimentos para ensinar com os conhecimentos a serem ensinados, a qual é gerida pelo conhecimento pedagógico do conteúdo, resulta na transformação do conhecimento do conteúdo a ser ensinado em conhecimento realmente ensinável. Ao mesmo tempo, essa interação testa as concepções até então aceitas, verifica a adequação ou não dos encaminhamentos metodológicos propostos e projeta as próximas decisões a serem tomadas. A essa altura da prática pedagógica, as etapas de compreensão e de transformação, integrantes do processo de raciocínio e ação pedagógica, ficam explícitas e atuam 
intensamente, relacionando-se intimamente tanto com a base de conhecimentos quanto com o conhecimento pedagógico do conteúdo.

Ao ser detectada a situação-problema prioritária e ao serem selecionados os conhecimentos que se aplicam a ela, o conhecimento pedagógico do conteúdo estabelece as estratégias de ação, e se passa, conforme propõe Gimeno Sacristán (1995), a decidir como esse conhecimento do conteúdo ensinável será abordado com os alunos. Identifica-se, aqui, mais uma vez, a participação evidente da etapa de transformação do processo de raciocínio e ação pedagógica, especificamente por meio dos subprocessos de representação de ideias e de seleção das estratégias de ensino.

Nota-se que, em todas as etapas anteriores, o conhecimento pedagógico do conteúdo limitou-se a intermediar um diálogo entre a base de conhecimentos e a prática pedagógica, em que os conhecimentos foram convocados e relacionados entre si sem a produção de um feedback a respeito do sucesso ou não das estratégias pedagógicas propostas. Ou seja, a participação do conhecimento pedagógico do conteúdo se resumiu em observar, analisar e propor, no campo abstrato, alternativas de intervenção, mas sem uma efetiva aplicação na prática, tal como propuseram Calderhead (1988) e Meirieu (2002).

Além disso, é muito provável que o conhecimento pedagógico do conteúdo tenha enfrentado alguns dilemas e situações-problema quando o estudante-professor ministrou, por exemplo, aulas para seus colegas na Instituição de Ensino Superior. Nessas situações, analisadas por autores como Carter (1990), Graber (1990) e Marcon et al. (2007), o conhecimento pedagógico do conteúdo teve oportunidade de estabelecer relações e de verificar, até determinado ponto, a aplicabilidade ou não de algumas estratégias para a solução de distintas situações-problema.

Entretanto, apenas agora o estudante-professor terá oportunidade de ver, de fato, suas estratégias pedagógicas aplicadas em situações reais de ensino e aprendizagem, com alunos em idade escolar, com interesses, necessidades e objetivos também reais. Nesse momento, é possível observar a participação da etapa de instrução do processo de raciocínio e ação pedagógica, já que o estudante-professor manifesta, por meio de suas ações, a maneira como desempenha suas funções docentes.

Do mesmo modo, a intervenção nas práticas pedagógicas permite avaliar não apenas o desempenho do estudante-professor, mas também a incidência de todas as etapas anteriores do programa de formação na 
sua personalidade docente e profissional, quais sejam: (1) as reflexões antes da prática pedagógica; (2) as etapas de compreensão e de transformação do processo de raciocínio e ação pedagógica; (3) a convocação e a interrelação dos conhecimentos dentro da base de conhecimentos por intermédio do conhecimento pedagógico do conteúdo; e (4) todas as demais estratégias pedagógicas propostas pelo programa de formação e implementadas pelos professores-formadores.

Acredita-se que esse feedback seja extremamente útil para o conhecimento pedagógico do conteúdo enquanto o estudante-professor interage com os alunos, pois continua estabelecendo relações instantâneas entre as informações do contexto, os conhecimentos da base de conhecimentos e as estratégias de intervenção que ele acabou de formular, no sentido de ratificar suas decisões ou de readequar alguns pontos que sejam necessários. Tendo em vista que o estudante-professor continua gerindo os conhecimentos em sua base de conhecimentos, e por ter iniciado sua intervenção na situação de ensino e aprendizagem, podem ser observadas, aqui, as etapas de transformação e de instrução do processo de raciocínio e ação pedagógica.

Durante a intervenção, verifica-se que, além dos conhecimentos selecionados, outros são continuamente convocados pelo conhecimento pedagógico do conteúdo na base de conhecimentos em decorrência das respostas e reações dos alunos, assim como sugerem Carter (1990) e Zeichner (1995). Para isso, participa outra modalidade de reflexão na ação, que, em vez de realizar um diagnóstico do contexto, avalia as estratégias implementadas. Essa avaliação, por realizar uma checagem constante e informal do alcance dos objetivos parciais da intervenção pedagógica, compartilha intimamente as proposições da etapa de avaliação do processo de raciocínio e ação pedagógica.

Ao mesmo tempo que convoca conhecimentos na base de conhecimentos, o conhecimento pedagógico do conteúdo é constantemente retroalimentado pelos resultados de sua intervenção na situação de ensino e aprendizagem. Nesse momento, além de serem gerados elementos referentes ao desempenho observável do estudante-professor (instrução do processo de raciocínio e ação pedagógica), o conhecimento pedagógico do conteúdo envia constantemente os conhecimentos recémconstruídos para arquivamento na base de conhecimentos. Concomitantemente, o caráter avaliativo da reflexão na ação faz repetidas análises dos 
resultados parciais da abordagem feita aos alunos e obtém informações relacionadas aos objetivos (avaliação do processo de raciocínio e ação pedagógica), as quais são reenviadas ao conhecimento pedagógico do conteúdo, que, por sua vez, e conforme a necessidade, reformula suas estratégias de intervenção.

Não obstante, também podem ser estabelecidas estreitas relações entre essa reflexão e a reflexão do processo de raciocínio e ação pedagógica, já que o estudante-professor revisa o contexto de ensino e aprendizagem, compara os objetivos estabelecidos inicialmente com aqueles obtidos até o momento e busca extrair dessa análise elementos que orientem suas decisões metodológicas, visando a encaminhar a prática pedagógica no sentido de alcançar os objetivos iniciais.

No caso de não serem alcançados os objetivos, o novo conhecimento é arquivado na base de conhecimentos, pois o estudante-professor aprende, pelo menos, que, em determinada situação, uma estratégia específica não gerou o efeito esperado. A partir disso, é aguçada a reflexão na ação, e o conhecimento pedagógico do conteúdo convoca, com critérios mais rigorosos, os conhecimentos na base de conhecimentos, promove uma interação mais apurada entre esses conhecimentos e o conhecimento recém-construído na tentativa anterior, e estabelece novas estratégias de intervenção. Por outra parte, no caso de serem alcançados os objetivos, o novo conhecimento construído é também arquivado na base de conhecimentos, e o conhecimento pedagógico do conteúdo estabelece como prioridade a solução da próxima situação-problema.

Independentemente de serem ou não alcançados os objetivos, o mais importante para o processo de construção do conhecimento pedagógico do conteúdo, como defende Sebren (1995), é que os conhecimentos construídos a partir da intervenção nas práticas pedagógicas serão enviados para a base de conhecimentos, fazendo com que sua estrutura adquira cada vez mais abrangência e robustez.

Essa relação entre os novos conhecimentos e a base de conhecimentos vem ao encontro do preconizado pela etapa da nova compreensão do processo de raciocínio e ação pedagógica, já que o estudante-professor começa a se dar conta de que, a partir da desestabilização inicial gerada por dilemas ou situações-problema, consegue reestruturar sua base de conhecimentos, seja reconstruindo aqueles que a integravam anteriormente, seja construindo novos a partir daqueles. 
A exemplo do que indica a literatura, ressalta-se que essa é a principal razão de ser do conhecimento pedagógico do conteúdo, pois conseguiu transformar os conhecimentos do conteúdo a serem ensinados, presentes na base de conhecimentos, em conhecimentos ensináveis, compreensíveis e úteis aos alunos (GRAÇA, 2001; MIZUKAMI, 2004; SEGALL, 2004; SHULMAN, 1987).

A análise aqui apresentada permite supor que, ao longo de todo o processo de idas e vindas entre a situação de ensino e aprendizagem e a base de conhecimentos, o conhecimento pedagógico do conteúdo, utilizando a riqueza de estímulos da prática pedagógica e as informações disponibilizadas pela reflexão na ação, assume a responsabilidade de estabelecer o elo entre (1) a recepção das informações das reflexões; (2) a convocação dos conhecimentos na base de conhecimentos; (3) a interação desses conhecimentos e dessas informações; (4) o estabelecimento de estratégias de ação; (5) a intervenção pedagógica na situação-problema; (6) a avaliação dos resultados; e (7) o arquivamento dos novos conhecimentos na base de conhecimentos.

Além disso, a realização das práticas pedagógicas permite que todas as etapas do processo de raciocínio e ação pedagógica sejam chamadas a participar da situação de ensino e aprendizagem, exercendo as funções de compreensão; transformação; instrução; avaliação; reflexão; e nova compreensão; e que possibilitem ao conhecimento pedagógico do conteúdo (1) acionar e inter-relacionar os conhecimentos na base de conhecimentos para o ensino; (2) promover a adaptação e a transformação do conhecimento do conteúdo a ser ensinado em conhecimento ensinável; e (3) fazer com que o estudante-professor construa conhecimentos sobre como ensinar diferentes assuntos, para diferentes alunos e em distintos contextos de ensino e aprendizagem. Essas considerações encontram respaldo no que tem sido proposto pela literatura ao longo dos anos (CARTER, 1990; CHEN, 2004; SEBREN, 1995; SEGALL, 2004; SHULMAN, 1987).

Em outras palavras, a evolução, a estruturação e a consolidação do conhecimento pedagógico do conteúdo do estudante-professor ficam evidentes, conforme descreveu Charlier (2001, p. 88), quando ele (1) "leva em conta de maneira deliberada o maior número de parâmetros possíveis da situação de formação considerada", articulando-os entre si de maneira crítica; (2) "considera uma ou várias possibilidades de condutas e toma 
decisões de planejamento de sua ação", colocando-as "em prática em situações concretas e recorre[ndo] a rotinas para assegurar a eficácia de sua ação"; (3) "ajusta sua ação de imediato se perceber que isto é necessário", experimentando novas condutas; e (4) "tira lições da sua prática", formulando novos esquemas de ação para serem utilizados em outras situações de ensino e aprendizagem.

Assim, a convergência dos integrantes da base de conhecimentos e das vivências do estudante-professor, para o conhecimento pedagógico do conteúdo, permitirá a reestruturação e o fortalecimento contínuo do próprio conhecimento pedagógico do conteúdo, bem como o desenvolvimento de diferentes conhecimentos, habilidades e competências dos futuros professores ao longo da formação inicial.

\section{Reflexões depois da prática pedagógica}

Para que os conhecimentos construídos durante a prática pedagógica, bem como o conhecimento pedagógico do conteúdo, sejam consolidados na base de conhecimentos e, principalmente, disponibilizados nas práticas pedagógicas futuras, a literatura aponta como fundamental que o estudante-professor recapitule a prática pedagógica que realizou, tomando-a como objeto de estudo e de análise crítica (CARTER, 1990; MIZUKAMI, 2004; PIMENTA, 1997, 2002; VALLI; RENNERTARIEV, 2002). Portanto, concluída a prática pedagógica e arquivados na base de conhecimentos os conhecimentos novos e os reconstruídos, é iniciada a última etapa do ciclo de reflexões a respeito da atuação pedagógica: a reflexão sobre a ação ou, como define Schön (1995, p. 83), a "reflexão sobre a reflexão-na-ação".

Esse processo é semelhante àquele da reflexão para a ação, pois o conhecimento pedagógico do conteúdo analisará uma situação de ensino e aprendizagem realizada em um momento anterior. A principal diferença, conforme destacam Behets e Vergauwen (2006), Nóvoa (1995) e Schön (1995), é que, enquanto na reflexão para a ação o conhecimento pedagógico do conteúdo processava informações e propunha estratégias de intervenção a partir de situações fictícias, simuladas ou ocorridas com os colegas ou professores, na reflexão sobre a ação esse processo se desenvolverá a partir de uma situação de ensino e aprendizagem ministrada pelo próprio estudante-professor. 
O caráter de avaliação, que foi utilizado na reflexão na ação, também volta à cena na reflexão sobre a ação, mas com outras características. As informações advindas das estratégias pedagógicas, implementadas nas situações de ensino e aprendizagem, não necessitarão ser enviadas instantaneamente para o conhecimento pedagógico do conteúdo, já que o estudante-professor não estará em ação diante dos alunos. Além disso, e como esclarecem Calderhead (1988) e Gimeno Sacristán (1995), o conhecimento pedagógico do conteúdo não necessitará limitar-se a utilizar unicamente os conhecimentos disponíveis na base de conhecimentos e as informações do contexto, como na reflexão na ação, mas poderá se apropriar também de conhecimentos e informações originados, por exemplo, no diálogo com colegas e professores-formadores, bem como no referencial teórico.

Por tudo isso, esse é considerado um momento privilegiado à medida que os estímulos, os dilemas e as situações-problema, por terem acontecido há pouco, ainda estão latentes na lembrança do estudante-professor e ricos em detalhes. Dessa forma, a reflexão sobre a ação oferece ao conhecimento pedagógico do conteúdo tanto os recursos quanto o tempo necessário para analisar a prática pedagógica sob diferentes ângulos e com diferentes critérios. Autores como Caires (2001), Calderhead (1988) e Pimenta (2002) explicam que, por intermédio dessas reflexões, o estudante-professor faz uma avaliação retrospectiva da prática pedagógica, recolhendo informações relativas a todos os aspectos que determinaram sua realização daquela forma e que influenciaram o alcance ou não dos objetivos iniciais por ele propostos.

Um dos aspectos que requer atenção do estudante-professor nesse processo de reflexão sobre a ação, e que, inclusive, é enfatizado pela literatura, é sua própria participação como professor-estudante no contexto de ensino e aprendizagem (BEHETS; VERGAUWEN, 2006; CAIRES, 2001; MIZUKAMI, 2004; SEBREN, 1995; TSANGARIDOU; O' SULLIVAN, 1994). De fato, torna-se fundamental que a reflexão sobre a ação ofereça informações privilegiadas que embasem a análise crítica sobre como o conhecimento pedagógico do conteúdo se saiu no cumprimento de suas funções de receber as informações da reflexão na ação; de convocar conhecimentos na base de conhecimentos; de processar e fazer interagir essas informações e esses conhecimentos; de estabelecer propostas de intervenção; e de implementá-las na situação de ensino e aprendizagem. 
Essa é, especificamente, a situação em que as etapas de avaliação e de reflexão do processo de raciocínio e ação pedagógica podem ser identificadas com mais clareza, visto que os focos da análise do estudante-professor são (1) o seu próprio desempenho e a influência das suas decisões metodológicas para os resultados da prática pedagógica (avaliação); bem como (2) a maneira como se desenvolveu o processo de ensino e aprendizagem, com a finalidade de reconstruí-lo e revivê-lo para que possa recapitular como os eventos ocorreram, quais emoções surgiram e como os aprendizados se deram (reflexão).

Vários estudiosos ressaltam que o sucesso dessa análise dependerá da diversidade e, fundamentalmente, da qualidade das estratégias utilizadas nas situações de ensino e aprendizagem, que necessitam gerar o questionamento, a dúvida e uma nova instabilidade momentânea na base de conhecimentos. Exemplos dessas estratégias podem ser as reflexões, os debates e o preenchimento de memoriais, que façam com que o estudante-professor se volte para sua prática pedagógica e a analise criticamente (BEHETS; VERGAUWEN, 2006; NÓVOA, 1995; PÉREZ-GÓMEZ, 1995; SEBREN, 1995; TSANGARIDOU; O’ SULLIVAN, 1994; VALLI; RENNERT-ARIEV, 2002).

A interação com colegas, nesses casos, é considerada "uma riqueza inestimável que permite a cada um apropriar-se de seu próprio saber e incorporar progressivamente o ponto de vista de outro para desenvolver-se" (MEIRIEU, 2002, p. 31), quando se "consolidam espaços de formação mútua, nos quais cada professor é chamado a desempenhar, simultaneamente, o papel de professor e de formando" (NÓVOA, 1995, p. 26). Além de contribuir com a formação dos colegas, os estudantesprofessores estarão mais suscetíveis para aprender com as vivências, os relatos e as experiências à sua volta, e passarão a absorver com mais naturalidade os novos conhecimentos que "pairam no ar" nos momentos de debate e de reflexão.

Um aspecto a destacar é que esses momentos, tanto individuais quanto coletivos, tanto de forma escrita quanto falada, configuram importantes oportunidades para que o estudante-professor faça um exercício de introspecção, para que veja seu conhecimento pedagógico do conteúdo refletido na prática pedagógica e que tome consciência dos conhecimentos que possuía, dos que reestruturou e dos que acabou de construir. Consoante enfatizam diferentes autores, essa autoanálise do processo de 
evolução dos conhecimentos permite que alguns deles se sobressaiam na base de conhecimentos, fortalecendo a estrutura de apoio do estudante-professor para suas próximas intervenções e, principalmente, consolidando seu conhecimento pedagógico do conteúdo e suas concepções sobre a matéria e o processo de ensino e aprendizagem (CARTER, 1990; ENNIS, 1994; GROSSMAN et al., 1989; PERDIGÃO, 2002; PÉREZ-GÓMEZ, 1995; PIMENTA, 1997; SEBREN, 1995; TSANGARIDOU; O' SULLIVAN, 1994).

Assim como ocorreu nas reflexões para e na ação, pode-se inferir que, na reflexão sobre a ação, é o próprio conhecimento pedagógico do conteúdo, mais uma vez, o responsável por intermediar o diálogo entre as informações da prática pedagógica, originadas na avaliação da reflexão sobre a ação; os conhecimentos, opiniões e pontos de vista dos colegas e dos professores-formadores; o referencial teórico; e a própria base de conhecimentos.

O que se observa, durante a reflexão sobre a ação e nos momentos subsequentes à prática pedagógica, é que o conhecimento pedagógico do conteúdo será submetido a um processo de autoanálise que adquirirá profundidade e complexidade à medida que, além de ser o mediador, será também objeto de análise. Nesse caso, o "novo" conhecimento pedagógico do conteúdo, reconstruído a partir do encerramento da prática pedagógica, é aplicado na análise daquele conhecimento pedagógico do conteúdo "antigo", utilizado durante sua realização.

É muito provável que situações controversas ocorram nesse confronto de diferentes versões do conhecimento pedagógico do conteúdo, o que poderá abalar as bases que o sustentam. Como resultado, podem ser confirmadas as decisões tomadas pelo conhecimento pedagógico do conteúdo na prática pedagógica ou podem ser questionadas tais decisões, à medida que o conhecimento pedagógico do conteúdo, utilizado na reflexão sobre a ação, apresente melhores alternativas para determinados dilemas, as quais não puderam ser propostas anteriormente devido à defasagem do conhecimento pedagógico do conteúdo utilizado durante a prática pedagógica.

De todo modo e, independentemente dos caminhos seguidos, ao fim desse processo, tanto o conhecimento pedagógico do conteúdo quanto a base de conhecimentos do estudante-professor não serão mais os mesmos de quando encerrou a prática pedagógica, e serão, provavel- 
mente, bem diferentes daqueles utilizados antes e durante a prática pedagógica.

Esse é, justamente, o típico exemplo de uma nova compreensão, preconizado pela etapa da nova compreensão do processo de raciocínio e ação pedagógica, visto que o estudante-professor passou a utilizar um novo conhecimento para refletir a respeito de um conhecimento antigo e, mais importante ainda, para refletir a respeito de sua própria atuação docente.

Dito isso, parte-se, neste momento, para uma confrontação mais direta e que justifica a interpretação de um implícito paralelismo entre as etapas do processo de raciocínio e ação pedagógica e as tarefas desempenhadas pelo conhecimento pedagógico do conteúdo nas práticas pedagógicas.

\section{Relações entre o processo de raciocínio e ação pedagógica e 0 conhecimento pedagógico do conteúdo nas práticas pedagógicas}

Mesmo que o próprio autor tenha evidenciado o desafio inerente à problemática (SHULMAN, 1993), as análises, realizadas anteriormente sobre o processo de raciocínio e ação pedagógica e sobre o conhecimento pedagógico do conteúdo, permitem inferir que essas duas propostas de Shulman (1987) mantêm estreita, recíproca e quase interdependente relação uma com a outra, de modo que se permeiam, se complementam e somam esforços no sentido comum de transformar os conhecimentos do conteúdo dos futuros professores em conhecimentos ensináveis, compreensíveis e úteis para os alunos.

Como observado na análise antes apresentada, as tarefas desempenhadas pelo conhecimento pedagógico do conteúdo, e que expõem a reciprocidade entre as práticas pedagógicas e a base de conhecimentos, são: (1) receber informações das reflexões; (2) convocar os conhecimentos na base de conhecimentos; (3) fazer interagir esses conhecimentos e essas informações; (4) estabelecer estratégias de ação; (5) intervir na situaçãoproblema; (6) avaliar os resultados; e (7) arquivar os novos conhecimentos na base de conhecimentos. Essas sete tarefas representam o caminho seguido pelo conhecimento pedagógico do conteúdo rumo à solução dos dilemas e das situações-problema nas práticas pedagógicas e, justamente, 
à transformação do conhecimento do conteúdo a ser ensinado em conhecimento ensinável e significativo aos alunos.

A fusão dessas sete tarefas do conhecimento pedagógico do conteúdo com as seis etapas do processo de raciocínio e ação pedagógica de Shulman (1987), a qual possibilita, inclusive, lançar luz de esclarecimento sobre a confusão reconhecida pelo próprio autor (SHULMAN, 1993), pode ocorrer, portanto, da seguinte maneira:

(1) a recepção das informações advindas das reflexões impõe aos estudantes-professores a necessidade de diversificar suas formas de compreender, de saber e de interpretar o assunto, relacionando-se, portanto, com a compreensão;

(2) a convocação dos conhecimentos na base de conhecimentos exige, além da diversificação das formas de interpretar o assunto, mudança nas próprias concepções do estudante-professor a respeito do tema, referindo-se, assim, tanto à transformação quanto à própria compreensão;

(3) a interação desses conhecimentos congrega, mais uma vez, tanto a compreensão quanto a transformação, pois continua gerando a desestabilização interna da base de conhecimentos do estudante-professor;

(4) o estabelecimento de estratégias de ação requer a participação de subprocessos da transformação, como a representação de ideias e a seleção de estratégias de ensino;

(5) a intervenção na situação-problema expõe o desempenho observável do estudante-professor, explicitando a maneira como organiza e gere o contexto de ensino e aprendizagem; se utiliza explicações e demonstrações claras e compreensíveis; como presta assistência e acompanhamento aos alunos; e como interage com eles, o que permite relacioná-la intimamente com a instrução;

(6) a avaliação dos resultados faz com que, principalmente por meio de processos informais, sejam coletadas informações sobre o alcance ou não dos objetivos, cujas tarefas são compartilhadas pela própria etapa da avaliação; assim como, quando o estudante-professor analisa sua própria participação no alcance desses objetivos e o seu desempenho no papel de professor-estudante, aplica a etapa de reflexão; e

(7) o arquivamento dos novos conhecimentos na base de conhecimentos se relaciona diretamente com a nova compreensão à medida que, a partir de uma desestabilização inicial, gerada por dilemas ou situaçõesproblema, o estudante-professor reestrutura sua base de conhecimentos, 
tanto reconstruindo aqueles que a integravam anteriormente quanto construindo novos a partir daqueles.

Percebe-se, dessa forma, tal como sugerem as fontes, que tanto a diversidade quanto a qualidade das práticas pedagógicas desenvolverão cada uma das etapas do processo de raciocínio e ação pedagógica, ao mesmo tempo que potencializarão, por intermédio do conhecimento pedagógico do conteúdo, a interação dos diferentes conhecimentos que integram a base de conhecimentos (BARBOSA-RINALDI, 2008; BEHETS; VERGAUWEN, 2006; PÉREZ-GÓMEZ, 1995; SCHÖN, 1995; SEBREN, 1995; WHIPPLE, 2002; WOODS et al., 2000; WRIGHT, 1999).

A partir disso, da incorporação de diferentes práticas pedagógicas em seus programas e da efetiva implementação por parte dos professores-formadores, os cursos de formação inicial de professores passam a manifestar seu esclarecimento quanto ao processo de construção do conhecimento pedagógico do conteúdo dos estudantes-professores, de que esse não se constrói "por acumulação, mas sim através de um trabalho de reflexividade crítica sobre as práticas e de (re)construção permanente de uma identidade pessoal" (NÓVOA, 1995, p. 25).

A inserção de todo esse sistema de práticas pedagógicas e de reflexões faz com que os programas de formação de professores possibilitem aos estudantes-professores, conforme explica Gimeno Sacristán (1995, p. 83), "a tomada de decisões, [a] realização de projetos para a prática, [e a] resolução de problemas ou análise da prática” a partir das próprias situações de ensino e aprendizagem (BEHETS; VERGAUWEN, 2006; WHIPPLE, 2002). Nesses casos, os estudantes-professores começam a narrar "histórias que vão significando o contexto escolar, antes não compreendido e, muitas vezes, desqualificado" (FONTANA; GUEDESPINTO, 2002, p. 14), e "aproximam-se da complexidade e contraditoriedade do trabalho educativo, experimentam-se na reflexão, no registro e na indagação desse fazer" (FONTANA; GUEDES-PINTO, 2002, p. 22). A atuação dos estudantes-professores, na formação inicial, aproxima-se, dessa forma, da própria atuação do professor na Educação Básica.

Assim, tanto a base de conhecimentos quanto o conhecimento pedagógico do conteúdo são reconstruídos constantemente, ficando à disposição do estudante-professor para serem requisitados em situações de ensino e aprendizagem posteriores, seja no momento de seu planeja- 
mento, na reflexão para a ação; seja durante a prática pedagógica, na reflexão na ação; seja após seu encerramento, na reflexão sobre a ação.

A prática pedagógica, assim interpretada, pode ser considerada o cerne da formação inicial de professores, pois, como ensinam diversos autores, viabiliza a participação e o desenvolvimento do conhecimento pedagógico do conteúdo, e é para ela que convergem as demais estratégias pedagógicas dos programas de formação (BARBOSA-RINALDI, 2008; BEHETS; VERGAUWEN, 2006; GIMENO SACRISTÁN, 1995; TARDIF; RAYMOND, 2000; VALLI; RENNERT-ARIEV, 2002; WHIPPLE, 2002; WRIGHT, 1999).

Ao mesmo tempo, e para que as práticas pedagógicas adquiram essa característica, a construção e o desenvolvimento do conhecimento pedagógico do conteúdo necessitam ser interpretados como alguns dos objetivos principais para a formação docente dos estudantes-professores pelos programas de formação inicial. Essas considerações encontram respaldo nas proposições de diferentes autores, uma vez que os gradativos desenvolvimento e aprofundamento do conhecimento pedagógico do conteúdo possibilitarão ao estudante-professor (1) transitar por todas as etapas do processo de raciocínio e ação pedagógica; (2) transformar seus conhecimentos do conteúdo em conhecimentos ensináveis, que sejam compreensíveis e úteis para seus alunos e que contribuam para seu aprendizado e para sua formação; e (3) alcançar os objetivos tanto das práticas pedagógicas quanto dos próprios programas de formação (CHEN, 2004; GRAÇA, 2001; MIZUKAMI, 2004; PARK; OLIVER, 2008; SEGALL, 2004; SHULMAN, 1987).

Essa é a natureza dinâmica e recíproca que caracteriza a relação entre os conhecimentos da base de conhecimentos do estudante-professor, as modalidades de práticas pedagógicas e o conhecimento pedagógico do conteúdo aplicado em cada um dos diferentes momentos de reflexão relacionados às situações de ensino e aprendizagem. Graça (1997) sintetiza a dinamicidade que pauta todos esses elementos quando esclarece que aprender a ensinar pode,

em certa medida, ser encarado como um processo de mudança conceitual, onde se consideram as concepções de ensino sustentadas pelos formandos, onde se apresentam concepções alternativas consistentes, onde se criam situações que promovam o conflito cognitivo e a insatisfação do formando com as concepções erradas ou inapropriadas e onde se reflita criticamente e se jus- 
tifique os argumentos que suportam as idéias ou as práticas de ensino (GRAÇA, 1997, p. 52).

A sucessiva gestão dessa complexa relação ao longo da formação inicial possibilitará ao estudante-professor aprofundar seu conhecimento pedagógico do conteúdo, construindo conhecimentos, competências e habilidades para lidar com diferentes situações de ensino e aprendizagem, delineando, gradativamente, os contornos de sua personalidade docente.

\section{Considerações finais}

Este ensaio procurou apresentar algumas ponderações sobre a relação existente entre as tarefas desempenhadas pelo conhecimento pedagógico do conteúdo e as etapas do processo de raciocínio e ação pedagógica, ambos propostos por Shulman (1987).

Para isso, foi analisada a participação do conhecimento pedagógico do conteúdo na interação da base de conhecimentos do estudanteprofessor com as práticas pedagógicas, por meio das suas funções de (1) receber, por intermédio das reflexões, as informações das situações de ensino e aprendizagem; (2) convocar os conhecimentos na base de conhecimentos; (3) fazer interagir esses conhecimentos e essas informações; (4) estabelecer estratégias de ação; (5) intervir na situação-problema; (6) avaliar seus resultados; e (7) arquivar os novos conhecimentos na base de conhecimentos.

Observou-se que (1) as reflexões influenciam determinadamente o conhecimento pedagógico do conteúdo no cumprimento de suas funções e no alcance dos objetivos das práticas pedagógicas; (2) o conhecimento pedagógico do conteúdo é o responsável por intermediar a relação entre as situações de ensino e aprendizagem e a base de conhecimentos, o que promove a ampliação e o fortalecimento dos conhecimentos que a integram; (3) as práticas pedagógicas constituem instâncias nas quais o conhecimento pedagógico do conteúdo pode ser instigado, analisado, avaliado e aperfeiçoado ao longo da formação inicial; e (4) mesmo não tendo sido explicitados por Shulman (1987), existem fortes indícios de permeabilidade e de reciprocidade entre suas duas propostas, nomeadamente, o 
processo de raciocínio e ação pedagógica e o conhecimento pedagógico do conteúdo.

Apesar do percurso seguido nesta abordagem, considera-se prudente ressaltar que a construção e a evolução do conhecimento pedagógico do conteúdo não serão lineares, não ocorrerão de uma hora para outra, e não será nos primeiros contatos com dilemas e situações-problema, comuns nas práticas pedagógicas, que o estudante-professor conseguirá implementar todas as funções do conhecimento pedagógico do conteúdo já elencadas.

Por isso, há necessidade de se desenvolver, paulatinamente, o conhecimento pedagógico do conteúdo dos futuros professores, em um processo de longo prazo e que demanda tempo, atenção e dedicação tanto por parte do programa de formação e dos estudantes-professores quanto, e fundamentalmente, por parte dos professores-formadores. Devido à clareza e à intrínseca relação com os assuntos aqui debatidos, considerase importante reproduzir a metáfora de Carbonneau e Hétu (2001). Segundo eles,

dirigir de dia e dirigir à noite são duas realidades muito diferentes. No primeiro caso, o campo visual apreendido apresenta uma grande envergadura. Temos a sensação de termos os olhos em torno de toda a cabeça, e o menor movimento que surge nesse campo é imediatamente detectado e uma parada imediatamente programada, haja o que houver. No segundo caso, o campo de visão é limitado ao clarão que se projeta, e a menor faísca de luz recebida ameaça ofuscar. Portanto, a previsão é mais difícil e de importância mais restrita. O ensino do especialista é comparável a dirigir de dia, enquanto o iniciante estaria em situação de direção noturna. Este dispõe apenas de alguns projetores conceituais para a iluminação e, mais raramente, de projetores extraídos da experiência. Por isso, há uma percepção truncada da realidade, e o menor imprevisto funciona como um clarão de luz que ofusca e vem interferir no seu controle de uma situação. Ele tem acesso a menos referências para dirigir e, normalmente, perceberá tarde demais os sinais que sugerem uma atitude a ser mudada, um programa a ser alterado. Nessa concepção, o desafio da formação inicial consistiria em reduzir a névoa que envolve as percepções dos iniciantes. Mas como? (CARBONNEAU; HÉTU, 2001, p. 74).

Essa metáfora, bem como os aspectos analisados neste ensaio, evidenciam que, além da importância de se considerar o processo de evolução do conhecimento pedagógico do conteúdo dos estudantes-professores, durante todo o período de formação inicial, algumas questões 
requerem atenção nesse contexto. Destacam-se: como fazer essa interação das práticas pedagógicas e da base de conhecimentos, por intermédio do conhecimento pedagógico do conteúdo, ser realmente viabilizada na formação inicial? Como aproveitar ao máximo a formação inicial para elevar o conhecimento pedagógico do conteúdo dos estudantes-professores aos maiores níveis possíveis, reduzindo a "névoa que envolve [suas] percepções"? Como possibilitar uma formação inicial de professores que permita a inserção lenta e gradativa dos estudantes-professores no mundo da docência? Como alcançar todos esses objetivos em apenas três ou quatro anos? Esses são, pois, alguns dos questionamentos que justificam o investimento no tema e que têm potencial para nortear futuros estudos a esse respeito. 


\section{REFERÊNCIAS}

ABELL, S. K.; LEDERMAN, N. G. Research on science teaching knowledge. In: ABELL, S. K.; LEDERMAN, N. G. (Org.). Handbook of research on science education. Mahwahm N.J.: Lawrence Erlbaum, 2007. p. 1105-1149.

ALTET, M. As competências do professor profissional: entre conhecimentos, esquemas de ação e adaptação, saber analisar. In: PAQUAY, L.; PERRENOUD, P.; ALTET, M.; CHARLIER, É. (Org.). Formando professores profissionais: Quais estratégias? Quais competências? Porto Alegre: Artmed, 2001. p. 23-35.

BARBOSA-RINALDI, I. P. Formação inicial em Educação Física: uma nova epistemologia da prática docente. Movimento, Porto Alegre, v. 14, n. 3, p. 185-207, 2008. Disponível em: <http://www.seer.ufrgs.br/index.php/Movimento/article/view/2431/4183>. Acesso em: 21 set. 2009.

BEHETS, D.; VERGAUWEN, L. Learning to teach in the field. In: KIRK, D.; MACDONALD, D.; O' SULLIVAN, M. (Org.). Handbook of Physical Education. London: Sage, 2006. p. 407-424.

CAIRES, S. Vivências e percepções do estágio no Ensino Superior. Minho: Grupo de Missão para a Qualidade do Ensino Aprendizagem, UM, 2001.

CALDERHEAD, J. The development of knowledge structures in learning to teach. In: CALDERHEAD, J. (Org.). Teachers' professional learning. London; Washington, D.C.: Falmer Press, 1988. p. 51-64.

CARBONNEAU, M.; HÉTU, J.-C. Formação prática dos professores e nascimento de uma inteligência profissional. In: PAQUAY, L.; PERRENOUD, P.; ALTET, M.; CHARLIER, É. (Org.). Formando professores profissionais: Quais estratégias? Quais competências? Porto Alegre: Artmed, 2001. p. 67-84.

CARTER, K. Teachers knowledge and learning to teach. In: SIKULA, R. H. M. H. J. (Org.). Handbook of research on teacher education. New York: MacMillan, 1990. p. 291-310.

CHARLIER, É. Formar professores profissionais para uma formação contínua articulada à prática. In: PAQUAY, L.; PERRENOUD, P.; ALTET, M.; CHARLIER, É. (Org.). Formando professores profissionais: Quais estratégias? Quais competências? Porto Alegre: Artmed, 2001. p. 85-102.

CHEN, W. Learning the skill theme approach: salient and problematic aspects of pedagogical content knowledge. Education, v. 125, n. 2, p. 194-212, Winter, 2004.

COCHRAN, K. F.; KING, R. A.; DERUITER, J. A. Pedagogical content knowledge: a tentative model for teacher preparation. In: ANNUAL MEETING OF THE AMERICAN EDUCATIONAL RESEARCH ASSOCIATION, 1991, Chicago. Anais... Chicago, 1991.

ENNIS, C. Knowledge and beliefs underlying curricular expertise. Quest, v. 46, n. 2, p. 164-175, 1994.

FONTANA, R. A. C.; GUEDES-PINTO, A. L. Trabalho escolar e produção do conhecimento. In: SHIGUNOV NETO, A.; MACIEL, L. S. B. (Org.). Desatando os nós da formação docente. Porto Alegre: Mediação, 2002. p. 6-22.

FORMOSINHO, J. A formação prática dos professores: da prática docente na instituição de formação à prática pedagógica nas escolas. Revista Portuguesa de Formação de Professores, v. 1, p. 37-54, 2001.

GIMENO SACRISTÁN, J. Consciência e ação sobre a prática como libertação profis- 
sional dos professores. In: NÓVOA, A. (Org.). Profissão professor. Porto: Porto, 1995. p. 63-92.

GRABER, K. C. The influence of teacher education programs on the beliefs of student teachers: general pedagogical knowledge, pedagogical content knowledge, and teacher education course work. Journal of Teaching in Physical Education, v. 14, n. 2, p. 157-178, Jan. 1995.

GRAÇA, A. O conhecimento pedagógico do conteúdo no ensino do basquetebol. 1997. 331 f. Tese (Doutorado em Ciências do Desporto) - Faculdade de Desporto, Universidade do Porto, Porto, 1997.

GRAÇA, A. O conhecimento pedagógico do conteúdo: o entendimento entre a pedagogia e a matéria. In: GOMES, P. B.; GRAÇA, A. (Org.). Educação Física e desporto na escola: novos desafios, diferentes soluções. Porto: FCDEF-UP, 2001. p. 107-120.

GRAÇA, A.; JANUÁRIO, C. Pedagogical content knowledge: a summary of the literature. In: CARREIRO-DA-COSTA, F.; DINIZ, J. A.; CARVALHO, L. M.; ONOFRE, M. $\mathrm{S}$. (Org.). Research on teaching and research on teacher education: proceedings of the Lisbon AIESEP International Seminar, 1996. Cruz Quebrada, Portugal: FMH, 2000. p. 80-86. GRIFFIN, L. L.; DODDS, P. S.; ROVEGNO, I. Pedagogical content knowledge for teachers: integrate everything you know to help students learn. Journal of Physical Education, Recreation and Dance, v. 67, n. 9, p. 58-61, 1996.

GROSSMAN, P. The making of a teacher: teacher knowledge and teacher education. New York: Teachers College Press, 1990.

GROSSMAN, P.; WILSON, S.; SHULMAN, L. Teacher of substance: subject matter knowledge for teaching. In: REYNOLDS, M. (Org.). Knowledge base for the beginning teacher. New York: Pergamon Press, 1989. p. 23-36.

HEGARTY, S. Teaching as a knowledge-based activity. Oxford Review of Education, v. 26, n. 3/4, p. 451-465, 2000. Disponível em:

$<$ http://search.ebscohost.com/login.aspx?direct=true\&db=aph\&AN=3893569\&site $=$ ehost-live\&scope $=$ site $>$. Acesso em: 14 set. 2009.

JENKINS, J. M.; VEAL, M. L. Preservice teachers' PCK development during peer coaching. Journal of Teaching in Physical Education, v. 22, n. 1, p. 49-68, Oct., 2002.

KIND, V. Pedagogical content knowledge in science education: perspectives and potential for progress. Studies in science education, v. 45, n. 2, p. 169-204, 2009.

MARCON, D.; NASCIMENTO, J. V.; GRAÇA, A. A construção das competências pedagógicas através da prática como componente curricular na formação inicial em Educação Física. Revista Brasileira de Educação Física e Esporte, São Paulo, v. 21, n. 1, p. 11 25, 2007. Disponível em:

<http://www.revistasusp.sibi.usp.br/pdf/rbefe/v21n1/v21n1a2.pdf>. Acesso em: 27 nov. 2009.

MEIRIEU, P. A pedagogia entre o dizer e o faz̧er: a coragem de começar. Porto Alegre: Artmed, 2002.

MIZUKAMI, M. G. Aprendizagem da docência: algumas contribuições de L. S. Shulman. Revista Educação, Santa Maria, v. 29, n. 2, p. 1-11, 2004. Disponível em: <http://coralx.ufsm.br/revce/revce/2004/02/a3.htm>. Acesso em: 17 ago. 2009.

NÓVOA, A. Formação de professores e profissão docente. In: NÓVOA, A. (Org.). Os professores e a sua formação. Lisboa: Dom Quixote, 1995. p. 13-33. 
PARK, S.; OLIVER, J. S. Revisiting the conceptualisation of pedagogical content knowledge (PCK): PCK as a conceptual tool to understand teachers as professionals. Research in Science Education, v. 38, p. 261-284, 2008. Disponível em:

<http://dx.doi.org/10.1007/s11165-007-9049-6>. Acesso em: $1^{\circ}$ out. 2009.

PERDIGÃO, A. L. Concepções pessoais de futuros professores sobre os processos de aprendizagem e de ensino. In: REALI, A. M.; MIZUKAMI, M. G. (Org.). Formação de professores, práticas pedagógicas e escola. São Carlos: EdUFSCar, 2002. p. 265-294.

PÉREZ-GÓMEZ, A. O pensamento prático do professor: a formação do professor como profissional reflexivo. In: NÓVOA, A. (Org.). Os professores e a sua formação. Lisboa: Dom Quixote, 1995. p. 93-114.

PERRENOUD, P. A prática reflexiva no ofício do professor: profissionalização e razão pedagógica. Porto Alegre: Artmed, 2002.

PIMENTA, S. G. Para uma re-significação da didática: ciências da educação, pedagogia e didática (uma visão conceitual e uma síntese provisória). In: PIMENTA, S. G. (Org.). Didática e formação de professores: percursos e perspectivas no Brasil e em Portugal. São Paulo: Cortez, 1997. p. 19-76.

PIMENTA, S. G. O estágio na formação de professores. 5. ed. São Paulo: Cortez, 2002.

SALAZAR, S. F. El conocimiento pedagógico del contenido como categoría de estudio de la formación docente. Revista Electrónica Actualidades Investigativas en Educación, v. 5, n. 2, p. 1-18, 2005. Disponível em:

$<$ http://revista.inie.ucr.ac.cr/articulos/2-2005/archivos/conocimiento.pdf $>$. Acesso em: 5 jul. 2010.

SCHÖN, D. A. Formar professores como profissionais reflexivos. In: NÓVOA, A. (Org.). Os professores e a sua formação. Lisboa: Dom Quixote, 1995. p. 77-91.

SEBREN, A. Preservice teachers' reflections and knowledge development in a fieldbased elementary physical education method course. Journal of Teaching in Physical Education, v. 14, p. 262-283, 1995.

SEGALL, A. Revisiting pedagogical content knowledge: the pedagogy of content/the content of pedagogy. Teaching and Teacher Education, v. 20, n. 5, p. 489-504, July, 2004.

SETTON, M. G. A teoria do habitus em Pierre Bourdieu: uma leitura contemporânea.

Revista Brasileira de Educação, Campinas, n. 20, p. 60-70, 2002. Disponível em: <http://www.anped.org.br/rbe/rbedigital/RBDE20/RBDE20_06_MARIA_DA_GR ACA_JACINTHO_SETTON.pdf>. Acesso em: 21 nov. 2008.

SHULMAN, L. S. Knowledge and teaching: foundations of the new reform. Harvard Educational Review, v. 57, n. 1, p. 1-27, 1987.

SHULMAN, L. S. Renewing the pedagogy of teacher education: the impact of subjectspecific conceptions of teaching. In: MONTEIRO, L.; VEZ, J. M. (Org.). Las didácticas especificas en la formación del profesorado. Santiago: Tórculo, 1993. p. 53-69.

SIEDENTOP, D. Content knowledge for Physical Education. Journal of Teaching in Physical Education, v. 21, n. 4, p. 368-377, 2002.

TANI, G. Vivências práticas no curso de graduação de Educação Física: necessidade, luxo ou perda de tempo? In: SIMPÓSIO DE PESQUISA EM EDUCAÇÃO FÍSICA, 6., 1995, Florianópolis. Anais... Florianópolis: UFSC, 1995.

TARDIF, M.; RAYMOND, D. Saberes, tempo e aprendizagem do trabalho no magistério. Educ. Soc., Campinas, v. 21, n. 73, p. 209-244, 2000. Disponível em: 
<http://www.scielo.br/scielo.php?script=sci_arttext\&pid=S010173302000000400013\&lng=pt\&nrm=iso >. Acesso em: 11 set. 2009.

TSANGARIDOU, N.; O' SULLIVAN, M. Using pedagogical reflective strategies to enhance reflection among preservice Physical Education teachers. Journal of Teaching in Physical Education, v. 14, p. 13-33, 1994.

VALLI, L.; RENNERT-ARIEV, P. New standards and assessments? Curriculum transformation in teacher education. Journal of Curriculum Studies, v. 34, n. 2, p. 201-225, 2002. WHIPPLE, C. E. Preservice teachers' views of content and pedagogical knowledge presented in the elementary component of a physical education teacher education program. 2002. $341 \mathrm{f}$. Tese (Doutorado em Filosofia) - Department of Philosophy, The Ohio State University, 2002. Disponível em:

$<$ http: / proquest.umi.com/pqdweb?did=764690441\&sid=4\&Fmt=2\&clientId=37541 $\&$ RQT $=309 \&$ VName=PQD $>$. Acesso em: 10 set. 2009.

WILSON, S. M. Introduction. In: SHULMAN, L. S.; WILSON, S. M.; HUTCHINGS, P. (Org.). The wisdom of practice: Essays on teaching, learning, and learning to teach. San Francisco: Jossey-Bass, 2004. p. 1-14.

WOODS, M.; GOC KARP, G.; ESCAMILLA, E. Preservice teachers learning about students and the teaching-learning process. Journal of Teaching in Physical Education, v. 20, n. 1, p. 15-39, 2000.

WRIGHT, S. A compatative view of teaching practice in Physical Education. International Sports Studies, v. 21, n. 1, p. 55-68, 1999. Disponível em:

$<$ http://www.la84foundation.org/

SportsLibrary/ISS/ISS2101/ISS2101f.pdf>. Acesso em: 15 set. 2009.

ZEICHNER, K. M. Novos caminhos para o practicum: uma perspectiva para os anos 90. In: NÓVOA, A. (Org.). Os professores e a sua formação. Lisboa: Dom Quixote, 1995. p. 115138.

ZEICHNER, K. M. Uma análise crítica sobre a "reflexão" como conceito estruturante na formação docente. Educ. Soc., Campinas, v. 29, n. 103, p. 535-554, 2008. Disponível em: <http://www.scielo.br/pdf/es/v29n103/12.pdf>. Acesso em: 24 nov. 2009.

\section{NOTA}

1 Apoio financeiro: Universidade de Caxias do Sul.

2 Os autores agradecem as contribuições dos Senhores Revisores anônimos para o aprimoramento deste texto.

Recebido: 02/03/2010

Aprovado: 15/09/2010

Contato:

Universidade de Caxias do Sul

Curso de Educação Física

Rua Francisco Getúlio Vargas, 1130

Bairro Petrópolis

Caxias do Sul - RS

CEP $95070-570$ 
